\title{
Corona mortis, aberrant obturator vessels, accessory obturator vessels: clinical applications in gynaecology
}

\author{
S. Kostov ${ }^{1}$, S. Slavchev ${ }^{1}$ (C), D. Dzhenkov², G. Stoyanov², N. Dimitrov³, A. Yordanov ${ }^{4}(\mathbb{D}$ \\ ${ }^{1}$ Department of Gynaecology, Medical University Varna, Bulgaria \\ 2Department of General and Clinical Pathology, Forensic Medicine and Deontology, Division of General and Clinical \\ Pathology, Faculty of Medicine, Medical University Varna "Prof. Dr. Paraskev Stoyanov", Varna, Bulgaria \\ ${ }^{3}$ Department of Anatomy, Faculty of Medicine, Trakia University, Stara Zagora, Bulgaria \\ ${ }^{4}$ Department of Gynaecologic Oncology, Medical University Pleven, Bulgaria
}

[Received: 5 July 2020; Accepted: 21 August 2020; Early publication date: 9 September 2020]

\begin{abstract}
Corona mortis (CMOR) is a heterogeneous and often dubious term that causes much confusion in medical literature, especially in regard to its modern day significance in pelvic surgery. Some authors define CMOR as any abnormal anastomotic vessel between the external iliac and obturator vessels, whereas others define it as any vessel coursing over the superior pubic branch, regardless whether it is a vascular anastomosis, an accessory obturator vessels, an obturator vessel related to the external iliac system or a terminal small vessel. There is no standard classification of CMOR and obturator vessels variations, although there are multitudes of classifications describing the diverse variations in the obturator foramen region. We define accessory obturator, aberrant obturator vessels and CMOR as different structures, as CMOR is an anatomical term that reflects a clinical situation rather than an anatomical structure. A new clinical classification for aberrant, accessory obturator vessels and CMOR is proposed regarding the anatomical variations, and the location of vessels to the deep femoral ring. The clinical significance of accessory obturator, aberrant vessels and CMOR is delineated in oncogynaecological and urogynaecological surgery. (Folia Morphol 2021; 80, 4: 776-785)
\end{abstract}

Key words: corona mortis, aberrant obturator vessels, accessory obturator vessels, deep femoral ring, oncogynaecology, urogynaecology

\section{INTRODUCTION}

Corona mortis (CMOR) is defined as any abnormal anastomotic vessels between the external iliac and obturator vessels [38]. Studies have shown that the definition of CMOR is heterogeneous and causes much confusion in medical literature [38]. Although in the past CMOR was defined as arterial anastomosis between an external iliac and an obturator artery, currently in medical reports the widely accepted definition includes the arterial and/or venous vascular anastomosis between an obturator and an external iliac vessel [2]. Moreover, some authors define CMOR as a connection between the external and internal iliac system, whereas others define it as any vessel coursing over the superior pubic branch, regardless whether it is a vascular anastomosis, an accessory obturator 
vessels, an obturator vessel related to the external iliac system or a terminal small vessel $[1,2,11,36,38]$. Additionally, there is no standard classification of CMOR and obturator vessels variations, although there are multitudes of classifications describing the diverse variations in the obturator foramen region $[1,15,36]$. Studying CMOR is crucial because of its association with a high risk of severe haemorrhage during surgeries. Various gynaecological procedures carry the risk of CMOR injury. The aim of this study is to define accessory obturator vessels (ACOVs), aberrant obturator vessels (AOVs) and CMOR. Moreover, we propose a new classification for the clinical use and delineate the clinical significance of ACOVs, AOVs and CMOR in oncogynaecological and urogynaecological surgery.

\section{OBTURATOR ARTERY ANATOMY AND VARIATIONS}

In the majority of cases, the obturator artery (OA) is a branch of the anterior division of the internal iliac artery [49]. It runs anteriorly and inferiorly on the pelvic wall and lies longitudinally to the obturator foramen on the medial part of the obturator internus muscle. The OA is located cranially to the obturator vein and caudally to the obturator nerve (ON) (Fig. 1) $[33,49,54]$.

The ureter lies medial to it. The OA gives branches within the pelvis before piercing the obturator foramen $[8,21,33,40,49,54]$. The OA gives branches to the obturator internus muscle, psoas muscle and to the iliac fossa for the iliacus muscle and the ilium. Sometimes the inferior vesical artery is replaced by caudal branch of the OA. The pubic branch arises before the obturator canal and runs cranially over the pubis to anastomoses with the pubic branch of the inferior epigastric artery and the contralateral artery (Fig. 2) [8, 21, 24, 33, 39, 40, 42, 49, 54].

There is, perhaps, no artery of proportionate size having as variable origin as the OA (Table 1$)[1,4,8$, $21,23,24,33,39,40,42,49,54]$.

Although studies reported different percentages for the OA origin variations, in the majority of cases the most common OA origin is from the IIA, followed by the inferior epigastric, external iliac artery, femoral artery $[8,21,33,39,40,54]$. When the OA arises from the IIA, it descends almost horizontally to the obturator foramen, whereas when the OA arises from the external iliac system, it crosses vertically over the superior pubic ramus and the external iliac vein. OA arising from the inferior epigastric artery is the com-

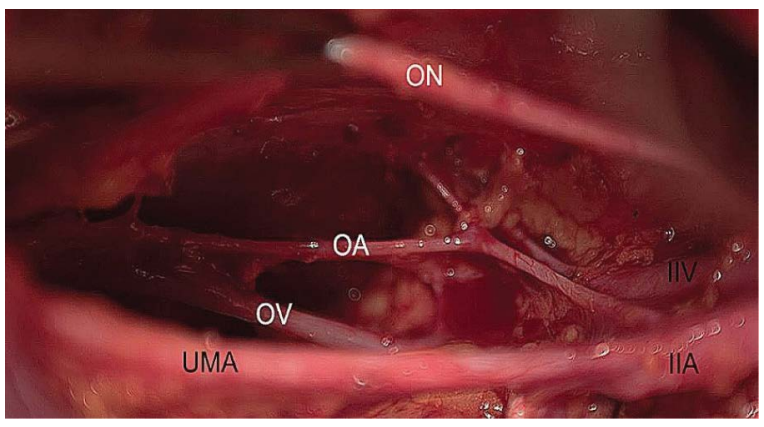

Figure 1. Obturator nerve, artery and vein topographical anatomy — open surgery (right pelvic side wall); $\mathrm{ON}$ — obturator nerve; $\mathrm{OA}$ - obturator artery; $\mathrm{OV}$ - obturator vein; IIV — internal iliac vein; IIA — internal iliac artery; UMA — umbilical artery.

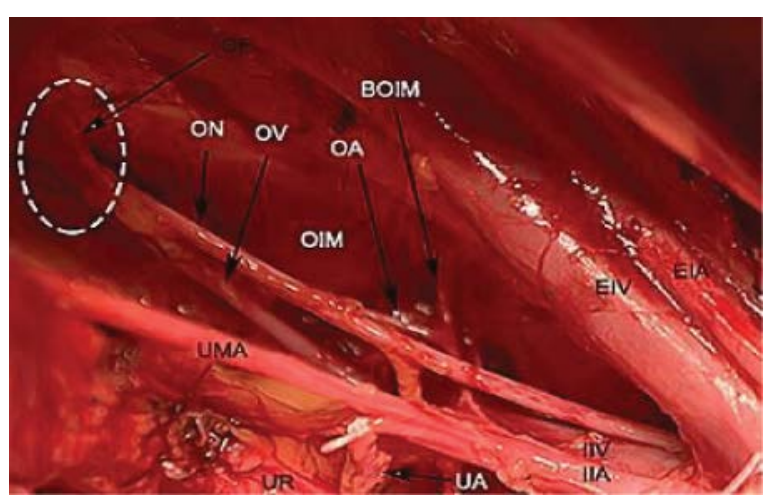

Figure 2. Obturator fossa anatomy - open surgery (right pelvic side wall); EIA — external iliac artery; EIV — external iliac vein; IIV — internal iliac vein; IIA — internal iliac artery; UA — uterine artery (cut and ligated); UR — ureter; UMA — umbilical artery; $\mathrm{ON}$ - obturator nerve; $\mathrm{OA}$ - obturator artery; $\mathrm{OV}$ — obturator vein; $\mathrm{OF}$ - obturator foramen; OIM — obturator internus muscle; BOIM - branch of obturator artery for obturator internus muscle.

Table 1. Obturator artery $(\mathrm{OA})$ origin variations $[1,4,8,21,23,24,33,39,40,42,49,54]$

\begin{tabular}{l}
\hline Origin from internal iliac artery (IIA) \\
\hline$O A$ arises separately from IIA before bifurcation \\
$O A$ arises from the anterior division of IIA \\
$O A$ arises from inferior gluteal artery \\
$O A$ arises from internal pudendal artery \\
$O A$ arises from posterior division of IIA \\
\hline Origin from external iliac artery (EIA) \\
\hline$O A$ arises directly from EIA \\
$O A$ is a branch of inferior epigastric artery \\
$O A$ arises as a double root from both IA and EIA \\
\hline
\end{tabular}

monest source of aberrant obturator artery (AOA) [33]. The incidence of an AOA arising from the inferior epigastric artery ranges from $20 \%$ to $34 \%$ [33]. 
Such an AOA has a great clinical significance. It is of a great calibre and has atypical passage through the superior pubic ramus. This artery passes posterior to the lacunar ligament and coursed the superior pubic ramus vertically to enter the obturator foramen. Therefore, OA arising from inferior epigastric artery is susceptible to injury during the dissection of the preperitoneal space using endoscissors or stapling of the mesh [23, 33]. Berberoglu et al. [4] reported on such an artery with diameter of $2.2 \mathrm{~mm}$. Darmanis et al. [11] reported that an AOA originating from the inferior epigastric artery or external iliac artery is present in $20-30 \%$ of hemipelvises and it is of a greater diameter on average than a CMOR when it is present. $O A$ arising from the external iliac artery is rare type of $O A$ origin $-1-2 \%[1,8,21,23,39$, $40,33,54]$. Other authors also reported on an AOA arising from inferior epigastric artery running superior to the inguinal ligament and lateral or medial to the femoral ring $[2,33]$. In conclusion, an AOA arising from the inferior epigastric artery is an extremely relevant substitute of the corona mortis.

Obturator artery can arise as a common trunk with most of the internal and external iliac arteries. Although rare, the $O A$ shares a common trunk with the inferior epigastric and the deep circumflex iliac artery. The trunk can arise in the femoral or external iliac region [40]. Although some authors reported more OA origin anomalies in females, the majority of studies showed no statistically significant difference between genders [39].

We define an AOA as an artery that originates from an external iliac artery or its branches and pierce the obturator membrane, not participating in anastomosis. There is no other OA.

An accessory $O A$ is the presence of an extra $O A$ in addition to the normal counterpart. An accessory OA pierces the obturator membrane, not participating in anastomosis [11, 37, 38]. We propose a simple classification of the aberrant and accessory obturator arteries with clinical significance (Fig. 3) [8].

In Figure 3, we divide type I and type II regarding the AOA location to the deep femoral ring, as an AOA medial to the deep femoral ring is closer to the urogynaecological field during surgery. An AOA lateral to the deep femoral ring is closer to the operative field during oncogynaecological procedures. Therefore, the probability of intraoperative injury depends on the locations of the AOA and the type of surgery. Type IV is included as it is of clinical significance in

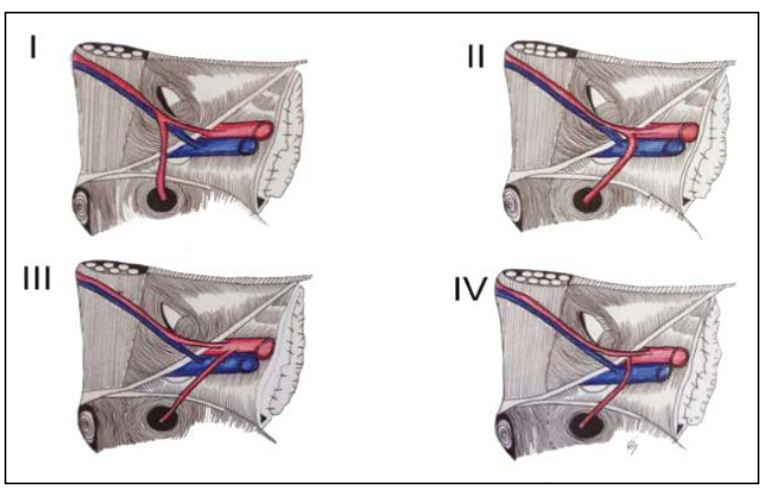

Figure 3. Aberrant obturator artery $(A O A)$ classification; Type I $A O A$ arising from the inferior epigastric artery. AOA is located medial to the deep femoral ring; Type II - AOA arising from the inferior epigastric artery. $A O A$ is located lateral to the deep femoral ring; Type III - AOA arising from the external iliac artery; Type IV AOA arising from the femoral artery.

oncogynaecology. Clinical applications of an AOA are described below. The accessory obturator artery classification is the same as the AOA one, except that there is a normal OA, arising from the IIA.

\section{OBTURATOR VEIN ANATOMY AND VARIATIONS}

The obturator vein (OV) arises in the adductor region and passes through the obturator foramen. It then proceeds posteriorly and superiorly on the lateral pelvic wall below the $\mathrm{OA}$ and drains into the internal iliac vein $[8,21,33,39,40,49,54]$. As mentioned above the obturator nerve (ON), $O A$, and OV run in that order, from above to below, in the lateral pelvic wall and piercing the obturator foramen. However, in medical literature different order in the neurovascular bundle has been described. In a study of 150 hemipelvises of 84 embalmed adult Korean cadavers, Won et al. [54] described the order ON-OV-OA in 5 cadavers and OA-ON-OV in 3 cadavers. In 25 of the specimens, two of these three structures (ON, OA, and OV) were twisted around each other in the lateral pelvic wall.

Classic anatomy texts pay less attention to the variations of veins than arteries. There are many reports of the OA origin variations, but less importance is given to the OV drain variations. It is believed that venous anomalies are more probable than an arterial one $[29,36]$.

We define an aberrant obturator vein as a vein that passes through the obturator foramen and drains in the external iliac vein or its tributaries, not participating in anastomosis. There is no other OV. 


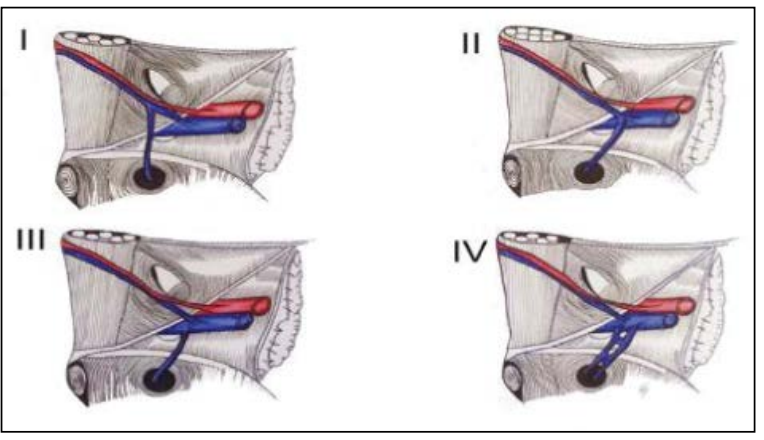

Figure 4. Aberrant obturator vein classification; Type I — aberrant obturator vein drains in the inferior epigastric vein. Aberrant obturator vein is located medial to the deep femoral ring; Type II - aberrant obturator vein drains in the inferior epigastric vein. Aberrant obturator vein is located lateral to the deep femoral ring; Type III aberrant obturator vein drains in the external iliac vein; Type IV double aberrant obturator vein drains in the external iliac vein.

An accessory $\mathrm{OV}$ is the presence of an extra OV in addition to the normal counterpart. An accessory OV passes through obturator membrane, not participating in anastomosis. We propose simple classification with a clinical significance of the aberrant and the accessory OVs (Fig. 4) [26, 54].

In Figure 4, we divide type I and type II regarding location to the deep femoral ring. An aberrant OV medial to the deep femoral ring is most likely to be injured during urogynaecology operations, whereas an aberrant OV lateral to the deep femoral ring during oncogynaecology procedures. Type IV is included, as the chance of damaging double aberrant OV is greater during pelvic lymphadenectomy. A double aberrant $\mathrm{OV}$ is located lateral to the deep femoral ring. Missankov et al. [26] reported in a cadaveric study, $2 \%$ of type IV of all specimens. The accessory OV classification is the same as the aberrant OV one, except that there is a normal OV, draining in the IIV.

\section{CMOR}

In medical literature, there is no consensus on CMOR terminology [41]. Berberoglu et at. [4] stated that some authors referred to the term "corona mortis" as the anastomosis between the OA and the pubic branch of the inferior epigastric artery, whereas others defined CMOR as the pubic branch of the OA [29]. Moreover, terms such as aberrant, accessory, communicating, variant obturator vessels were used to clarify CMOR [12, 31, 38, 41]. Additionally, some authors termed CMOR as any vessel coursing over the superior pubic branch, regardless whether it is a vascular anastomosis, an obturator vessel related to the external iliac system or a terminal small vessel $[2,36]$.

We prefer to keep the description by Darmanis et al. [11], Sanna et al. [38] and Drewes at al. [12], as the term "corona mortis" is any abnormal anastomotic vessel, located behind the superior pubic ramus and on the posterior aspect of the lacunar ligament, between an obturator vessel (part of to the internal iliac system) and an external iliac vessel $[11,12,38]$. CMOR should measure $2 \mathrm{~mm}$ or more $[32,46]$. CMOR could be in close relationship with the loose edge of the lacunar ligament and the neck of the femoral hernia sac $[4,11,32,41]$. The close relation between $\mathrm{CMOR}$, lacunar ligament and femoral ring could become a matter of great concern to the orthopaedic surgeon, urologist, gynaecologist and general surgeon [32]. Sarikcioglu et al. [41] measured the average distance between the arch of the lacunar ligament and the CMOR and found this average to be $12.18-3.55 \mathrm{~mm}$. Accessory obturator and AOVs are excluded as these originate from the external iliac or inferior epigastric system and pierce the obturator membrane, not participating in anastomosis [38]. Our concept of separation is that CMOR is an anatomical term that reflects a clinical situation rather than an anatomical structure [2]. Therefore, CMOR, AOVs and ACOVs are at various risk of damage during different surgical procedures. We proposed a clinical classification of CMOR (Fig. 5). Type III CMOR is shown in Figure 6.

\section{CLINICAL APPLICATIONS OF AOVS, ACOVS AND CMOR IN GYNAECOLOGY}

In oncogynaecology, Selcuk et al. [43] reported that the term "corona mortis" was questionable. They concluded that the retro-pubic vascular anastomoses were easily seen after a careful and tiny dissection over the external iliac artery below the inguinal ligament. In their opinion, an injury to $C M O R$ rarely occurs during pelvic lymphadenectomy as they had only 6 CMOR injuries among 96 pelvic lymphadenectomies. The bleeding was easily controlled [43]. According to other authors CMOR is exposed and at risk of injury during pelvic lymphadenectomy [15, 32]. In our opinion, there is a low risk of damaging CMOR during pelvic lymphadenectomy at the external iliac region for endometrial, ovarian and cervical cancer. Anatomical landmarks for performing systematic oncogynaecological pelvic lymphadenectomy in the external iliac region are: ventrally - drain of deep 


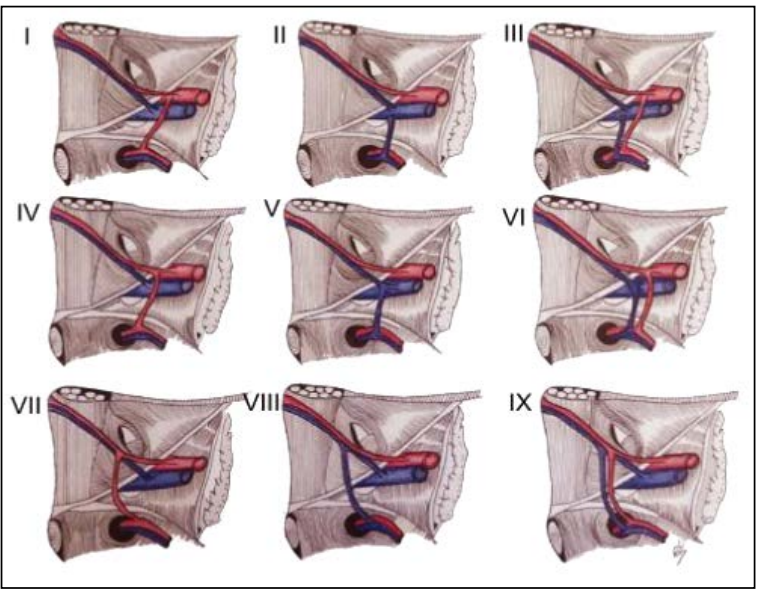

Figure 5. Corona mortis (CMOR) classification; Type I - CMOR between obturator artery (OA) and external iliac artery; Type II CMOR between obturator vein (OV) and external iliac vein; Type III CMOR between both obturator vessels and external iliac vessels; Type IV - CMOR between inferior epigastric artery and OA; Type V $\mathrm{CMOR}$ between inferior epigastric vein and $\mathrm{OV}$; Type $\mathrm{VI}-\mathrm{CMOR}$ between both obturator vessels and inferior epigastric vessels (Type IV, V and VI anastomotic vessels are located lateral to the deep femoral ring); Type VII — CMOR between OA and inferior epigastric artery; Type VIII - CMOR between OV and inferior epigastric vein; Type IX - CMOR between both obturator vessels and inferior epigastric vessels (Type VII, VIII and IX anastomotic vessels are located medial to the deep femoral ring).

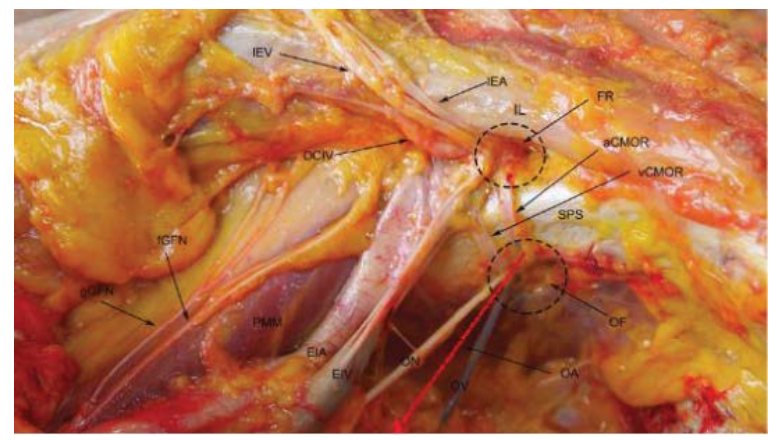

Figure 6. Arterial corona mortis (CMOR) and venous CMOR between obturator artery/vein and external iliac artery/vein. Fresh cadaver. Type III; PMM — psoas major muscle; EIA — external iliac artery; EIV — external iliac vein; gGFN — genital branch of genitofemoral nerve; fGFN — femoral branch of genitofemoral nerve; DCIV — deep circumflex iliac vein; IEV — inferior epigastric vein; IEA — inferior epigastric artery; IL — inguinal ligament; FR - deep femoral ring; OF — obturator foramen; $\mathrm{ON}$ - obturator nerve; $\mathrm{OA}$ - obturator artery(severed during dissection); $\mathrm{OV}$ obturator vein; aCMOR — arterial corona mortis; vCMOR venous corona mortis; SPS — superior pubic ramus.

circumflex iliac vein (DCIV), dorsally - common iliac artery bifurcation, laterally - genitofemoral nerve on the iliopsoas muscle, medially — obliterated umbilical artery $[9,43]$. DCIV is ventral border as removal of circumflex iliac nodes distal to the DCIV in external iliac region for cervical cancer (FIGO stage la, Ila) is not

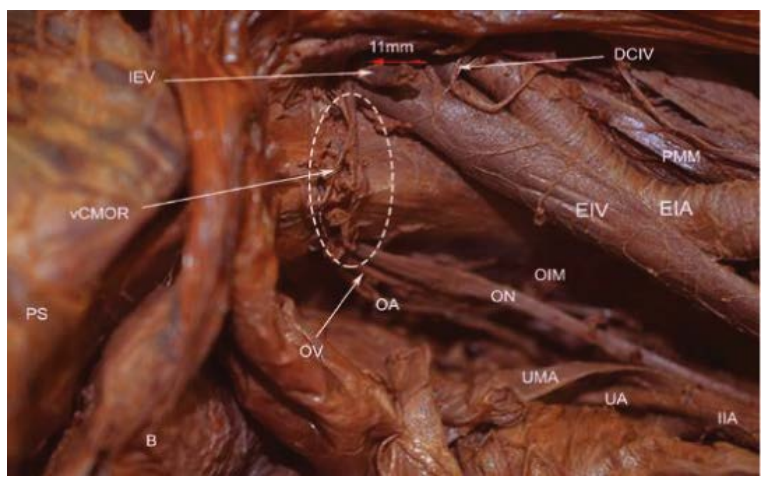

Figure 7. Venous corona mortis between obturator vein and inferior epigastric vein (right pelvic side wall). The distance between deep circumflex iliac vein and inferior epigastric vein is measured $11 \mathrm{~mm}$. Embalmed cadaver. Type V; EIA — external iliac artery; EIV — external iliac vein; PMM — psoas major muscle; OIM obturator internus muscle; IIA — internal iliac artery; UA — uterine artery; UMA — umbilical artery; $\mathrm{ON}$ - obturator nerve; $\mathrm{OA}$ obturator artery; OV — obturator vein; B — bladder; PS — pubic symphysis; IEV — inferior epigastric vein; DCIV — deep circumflex iliac vein; $\mathrm{vCMOR}$ - venous corona mortis.

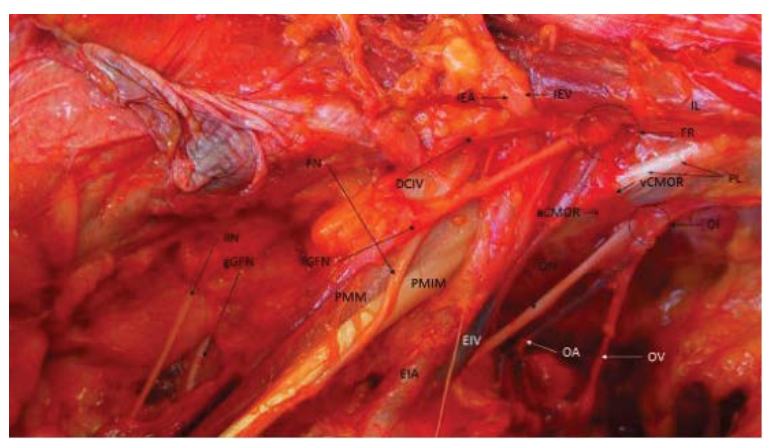

Figure 8. Arterial and venous corona mortis (CMOR) between external iliac and obturator vessels (left pelvic side wall). Rare case of CMOR proximal to the deep circumflex iliac vein. Fresh cadaver. Type III; EIA — external iliac artery; EIV — external iliac vein; PMM — psoas major muscle; PMIM — psoas minor muscle; FN — femoral nerve; IIN — ilioinguinal nerve; gGFN — genital branch of genitofemoral nerve; fGFN — femoral branch of genitofemoral nerve; DCIV - deep circumflex iliac vein; $\mathrm{ON}$ - obturator nerve; $\mathrm{OA}$ - obturator artery; $\mathrm{OV}$ - obturator vein; $\mathrm{OF}$ - obturator foramen; FR — deep femoral ring; aCMOR - arterial corona mortis; vCMOR — venous corona mortis; IL — inguinal ligament; PL — pectineal ligament; IEV — inferior epigastric vein; IEA — inferior epigastric artery.

necessary for three reasons - might not be regional lymph nodes, greater risk of lymphedema and low metastatic rate [52]. Studies reported similar findings for endometrial and ovarian cancer $[30,48,50]$. Therefore, visualisation of DCIV is enough to complete ventral dissection in the external iliac region. The DCIV drains in the external iliac vein, approximately $1 \mathrm{~cm}$ proximal to the inferior epigastric vein, so injury to CMOR should be avoided (Figs. 7, 8). 
As shown in Figure 7, the DCIV is proximal to the inferior epigastric vein. The distance between vessels was measured - $11 \mathrm{~mm}$ (Fig. 7). Consequently, during pelvic oncogynaecological lymphadenectomy at the external iliac region, injury to the CMOR distal to the DCIV is less likely to occur, especially for anastomotic vessels between the obturator and the inferior epigastric system. In medical literature, there are no studies comparing the frequency of AOVs, ACOVs, and CMOR distal or proximal to the DCIV. However, figures from the majority of studies showed CMOR, AOVs, ACOVs to be distal to the DCIV [15, 31, 39, 41]. Nevertheless, meticulous dissection should be performed until the level of the DCIV is reached (Fig. 8).

The risk of injury of AOVs, ACOVs and CMOR is high during pelvic lymphadenectomy in the obturator region. Anatomical landmarks for performing pelvic lymphadenectomy in the obturator region are: cranially - caudal wall of the external iliac vein, caudally - the obturator vessels, ventrally - the pubic bone together with the levator ani and the obturator muscle, where the obturator nerve leaves the pelvis through the obturator canal, dorsal - the common iliac vessels bifurcation, medial - the urinary bladder, lateral — the obturator internus muscle [9]. Meticulous and careful lymph node dissection is required in the ventral and caudal border of obturator region in order to preserve AOVs, ACOVs, and CMOR. As shown in Figure 8, the risk of damaging CMOR is elevated in the obturator and external iliac region during pelvic lymphadenectomy. CMOR is proximal to the deep circumflex iliac vein, as the anastomosis is between obturator and external iliac system.

The origin of an AOA from the femoral artery is rare and no prevalences have been established [24]. However, studies reported the rate of AOA arising from the femoral artery to be between $0.15 \%$ and $1.66 \%[1,24,33,40]$. In Figure 3 we included an AOA arising from the femoral artery (type IV), as it is of major clinical significance in two oncogynaecological procedures: inguinofemoral lymphadenectomy and sentinel lymph node biopsy in the inguinofemoral region [49]. The lymphatic system in the inguinal region can be divided into two distinct groups: superficial and deep inguinal lymph nodes. The superficial inguinal lymph nodes are located beneath the Camper fascia and superficial to the fascia lata of the thigh, whereas the deep inguinal nodes lie beneath the fascia lata along the femoral vein [7]. An AOA arising from the femoral artery is at high risk of injury during superficial and deep inguinal lymph nodes dissection. The uppermost deep inguinal lymph node located within the femoral canal and under the inguinal (Poupart) ligament is called Cloquet's node [3]. Cloquet's node was believed to be the link between inguinal and iliac/obturator nodes and the sentinel lymph node for vulvar cancer [44]. Currently, studies report that Cloquet's node has no particular surgical relevance and is considered an inconstant lymph node, being absent in approximately $50 \%$ of the cases and, when present, unilateral in approximately $30 \%[6,25]$. Although Cloquet's node is not consistently present, an examination for its presence should be performed by cranial retraction of the inguinal region over the femoral canal [5]. A Cloquet's node dissection carries the risk of injuring an AOA arising from femoral artery, medial circumflex femoral artery or profunda femoral. Although the node is medial to an AOA arising from femoral artery, the surgeon should be familiar with OA origin anomalies in the region.

In our opinion, ACOVs and AOVs are at higher risk of injury than CMOR in the external iliac region, as they are more likely to occur proximal to the DCIV and lateral to the deep femoral ring. AOVs cross the superior pubic ramus more obliquely and at a posterior position compared to CMOR [11]. Moreover, damage to ACOV and AOVs could be more precarious than CMOR. In the majority of cases, the average diameter of AOVs is greater than CMOR [11, 18, 54]. ACOVs, AOVs and CMOR lateral to the deep femoral ring are at major risk of damage during pelvic lymphadenectomy, as they are in the surgical field.

In urogynaecology, AOVs, ACOVs and CMOR are at risk of injury during stress urinary incontinence procedures - minimally invasive midurethral sling - the tension-free vaginal tape (TVT), Transobturator tape (TOT), TVT Secur (a single-incision sling device) and retropubic colposuspension - Burch procedure.

For many years, Burch colposuspension (first introduced in 1961) was a well-accepted technique for surgical management of stress urinary incontinence (SUI), especially when it was associated with urethral hypermobility. It was considered as the "gold standard" for the treatment of SUI [52]. Burch procedure surpassed in popularity in the early 2000s after the advent of the minimally invasive midurethral sling [14]. Although antimesh media and statements by the United States Food and Drug Administration in recent years have led to some patients requesting mesh-free surgery, Burch procedure remains an op- 
tion for secondary treatment of SUI [19, 52]. Burch colposuspension is performed through laparotomy or laparoscopy [52].

The Retzius (retropubic) space is dissected. Once the retropubic space is dissected, the bladder neck and the pubocervical fascia are identified. The surgeon places 2 bilateral nonabsorbable sutures through the pubocervical fascia and vaginal muscularis, without passing through the vaginal epithelium - one at the level of the midurethra and other at the urethrovesical junction. Sutures are fixed to the Cooper's pubic ligament $[19,53]$.

Cooper [10] originally described Pectineal ligament or Cooper's pubic ligament. He stated that the Cooper's ligament was a ligamentous expansion, which formed a remarkably strong ridge above the iliopectineal line $[10,47]$. There is no consensus about the origin of pectineal ligament. Faure et al. [13] reported that the pectineal ligament adhered to the periosteum of the superior pubic ramus, covered the pectineal line of the pubis, and stretched dorsally from the pubic tubercle and the iliopubic eminence $[13,47]$. The pectineal ligament was the dorsal border of the deep femoral ring and the lacunar (Gimbernat) ligaments formed the medial border [34]. Steinke et al. [47] reported that the pectineal ligament was attached ventrally to the pectineus muscle and it was attached to both the iliopsoas fascia and obturator fascia, whereas dorsally both fasciae were free of the pectineal ligament. Cranially, the pectineal ligament was connected to the inguinal ligament by the lacunar ligament [47]. Faure et al. [13] concluded that the mean length of pectineal ligament was $53 \mathrm{~mm}$. It was thicker in two regions - at its medial insertion or between the external iliac vessels and the pubic spine [13]. They reported that during Burch colposuspension stitches should be located near to the iliac vessels and $4 \mathrm{~cm}$ lateral to the medial insertion of the ligament, where it has its greatest thickness [13]. According to other study, the medial part of pectineal ligament close to the pubic tubercle was the thickest section and it became thinner while extending laterally [34]. In a study of 11 female unembalmed female cadavers, Kinman et al. [19] reported that the mean distance from the most lateral stitch in Cooper's pubic ligament to the obturator bundle was $25.9 \pm 7.6 \mathrm{~mm}$ and to the external iliac vessels was $28.9 \pm 9.3 \mathrm{~mm}$, and in some instances, these structures were less than $15 \mathrm{~mm}$ away. Pulatoglu et al. [34] measured the total length of the pectineal ligament $-5.9 \pm 0.76 \mathrm{~cm}$ on the left and

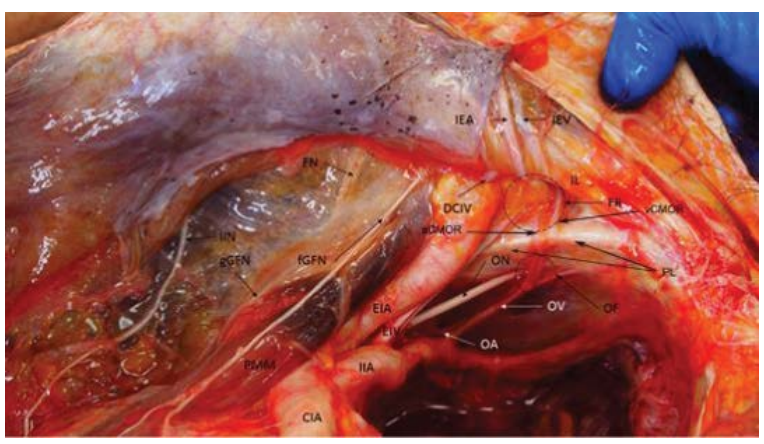

Figure 9. Arterial and venous corona mortis (CMOR) between inferior epigastric and obturator vessels (left pelvic side wall). CMOR is located medial to the deep femoral ring. Fresh cadaver. Type IX; CIA — common iliac artery; PMM — psoas major muscle; IIA internal iliac artery; EIV — external iliac vein; EIA — external iliac artery; IIN — ilioinguinal nerve; FN — femoral nerve; gGFN genital branch of genitofemoral nerve; fGFN — femoral branch of genitofemoral nerve; $\mathrm{ON}$ - obturator nerve; $\mathrm{OA}$ - obturator artery; OV — obturator vein; OF — obturator foramen; $\mathrm{PL}$ - pectineal ligament; FR - deep femoral ring; vCMOR - venous corona mortis; aCMOR — arterial corona mortis; IL — inguinal ligament; DCIV — deep circumflex iliac vein.

$6.5 \pm 1.14 \mathrm{~cm}$ on the right side. From the midpoint of the right pectineal ligament, the mean distance to the right CMOR was $2.37 \pm 0.63 \mathrm{~cm}$ and the mean distance to the left CMOR was $2.15 \pm 0.48 \mathrm{~cm}$ [34].

From these studies, we can conclude that during Burch colposuspension, AOVs, ACOVs and CMOR are at great risk of injury, especially if they pass medial to the deep femoral ring (Fig. 9).

In Figure 9, CMOR is located medial to the deep femoral ring and in close proximity to the most lateral stitch in the pectineal ligament. The incidence of AOVs, ACOVs and CMOR medial to the deep femoral ring varies in medical literature (5-42.5\%). A recent study reported that the AOA lay medial to the deep femoral ring in $10 \%$ of cases [23]. Skandalakis and Skandalakis [45] stated $40 \%$ percentage of AOA passing medial to the deep femoral ring. Another study reported an artery that passed through the medial side of the deep femoral ring in $5 \%$ of the specimens observed. Moreover, there were comparatively larger veins, which ran medially to the deep femoral ring and opened into the external iliac vein (found in $42.5 \%$ ) [8]. Injury of AOVs, ACOVs and CMOR lateral to the deep femoral ring during Burch colposuspension is possible, but less likely to occur. In the majority of cases AOVs, ACOVs and CMOR are located lateral to the deep femoral ring (60-90\%) $[23,33,45]$.

Furthermore, AOVs, ACOVs and CMOR are at risk of damaged during operations for vaginal wall de- 
scent, uterovaginal prolapse and neovaginal reconstruction $[34,47]$. Studies reported that pectopexy for pelvic organ prolapse is feasible procedure because the surgeon used a wide area in the pelvis and the strong nature of the pectineal ligament would decrease the postoperative recurrence rates $[17,34]$. The pectineal ligament is the target for neovaginal attachment in Mayer-Rokitansky-Küster-Hauser syndrome. The syndrome is related with uterus aplasia and variable degrees of vaginal hypoplasia of its upper portion. Although different materials are used for creation of neovaginal attachment, sigmoid grafts are most common $[28,47]$.

Minimally invasive procedures, such as the TVT sling (introduced in 1998), the TOT sling (2002) and the TVT-Secur are used for treatment of SUI [46]. They involve the placement of slings under the midurethra through a retropubic (TVT) or transobturator (TOT) approach [46]. The TVT is considered a minimally invasive procedure that involved passage of needles through small vaginal and suprapubic skin incisions [27]. The TOT is a minimally invasive procedure, based on an entirely new concept of positioning of tape under the middle urethra horizontally through the obturator foramen [20]. The TVT-Secur is less invasive short tape method as anchoring the minitape in the obturator muscle avoids a full needle passage. The TVT-Secur has two suggested approaches - U-retropubic and lateral Hammock (obturator) [22]. In the $\mathrm{U}$-approach, the tape is pushed along the periost behind the arc of the pubic bone at an angle of $45^{\circ}$, whereas in the Hammock Approach, the tape is pushed towards the obturator foramen [14]. Although TOT (the retropubic space is not entered, the needle tip penetrates the obturator externus muscle, the obturator membrane, and then rotates around the medial aspect of the pubic ramus) is associated with lower rate of AOVs, ACOVs and CMOR injury, studies reported damage to these vessels in all type of sling procedures $[14,20,22,27,35,46]$. Montoya et al. [27] stated that during TVT-Secur procedure, the closest distance from the $45^{\circ}$ and $90^{\circ}$ anchor points to the ACOV was 1.6 and $1.5 \mathrm{~cm}$, respectively. They described ACOV and CMOR as the same structure [27]. In a cadaveric study, Stavropoulou-Deli [46] stated that the average distance from the symphysis pubis to arterial CMOR was $52.4 \mathrm{~mm}$ and venous CMOR was $46.7 \mathrm{~mm}$ [27]. Darmanis et al. [11] reported an average distance between the CMOR and the symphysis pubis $40 \mathrm{~mm}-96 \mathrm{~mm}$, while Tor-

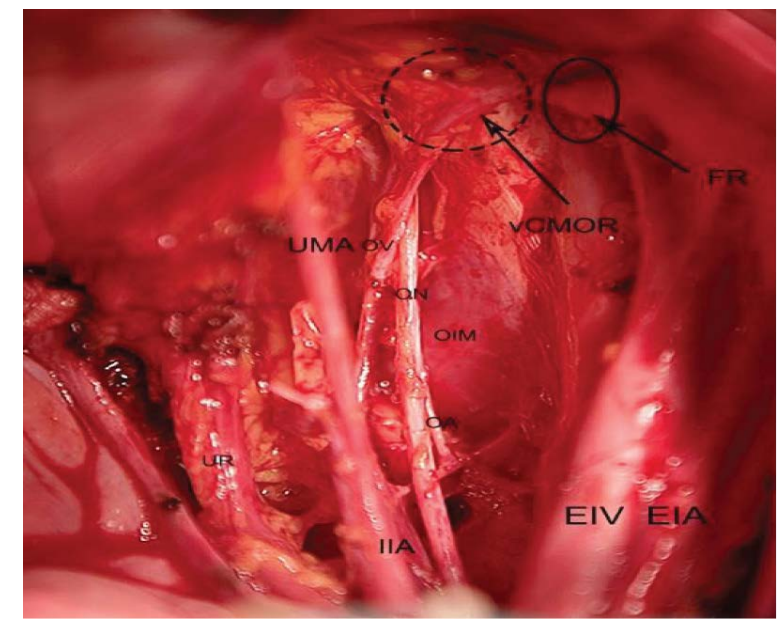

Figure 10. Venous corona mortis (CMOR) between OV and inferior epigastric vein. The anastomosis is located medial to the deep femoral ring — open surgery. Type V; EIV — external iliac vein; EIA external iliac artery; IIA — internal iliac artery; UR - ureter; UMA — umbilical artery; $\mathrm{ON}$ — obturator nerve; $\mathrm{OA}$ — obturator artery; $\mathrm{OV}$ - obturator vein; OIM — obturator internus muscle; $\mathrm{FR}$ - deep femoral ring; vCMOR - venous corona mortis.

netta et al. [51] reported $30 \mathrm{~mm}-90 \mathrm{~mm}$ [11, 36, 51]. The majority of authors concluded that average distance from the symphysis pubis to AOVs, ACOVs and CMOR exceeded $30 \mathrm{~mm}[25,46]$. Consequently, during TVT and TVT-Secur (U-approach) the tape is placed at a distance of $25 \mathrm{~mm}-30 \mathrm{~mm}$ from the symphysis pubis $[14,46]$. Larsson et al. [22] reported a complication of CMOR during TVT-Secur procedure [20]. Authors commented Larsson et al. [22] case and concluded that the injury of the CMOR happened in the attempt to place the TVT-Secur ${ }^{\mathrm{Tm}}$ more upwardly, similar to the tape applied in the $U$ position $[14,16$, 20]. Gobrecht et al. [14] stated that the $45^{\circ}$-angle insertion could damage the AOVs, ACOVs and CMOR. Injuring the AOVs, ACOVs and CMOR could be avoided by inserting the tape in either a $0^{\circ}$ angle (classic retropubic TVT) or a $90^{\circ}$ angle (TVT-O, obturator) [14]. In our opinion, injury to AOVs, ACOVs and CMOR during TVT-sling procedures is more likely to occur if they are located medial to the deep femoral ring, as the closer proximity to the symphysis pubis (Fig. 10).

\section{CONCLUSIONS}

Aberrant obturator vessels, ACOVs and CMOR are encountered during different types of gynaecological operations. Intraoperative injury to AOVs, ACOVs and CMOR depends on the type of surgery and vessels' location behind the superior pubic ramus, and posterior aspect of the lacunar ligament. Our new 
clinical classification might help gynaecologist to be familiar with AOVs, ACOVs, CMOR variations and to avoid injury during surgery.

\section{Acknowledgements}

The authors wish to thank Miglena Nevyanova Drincheva for art work and d-r Ivan Mihailov for his professional pictures.

\section{Conflict of interest: None declared}

\section{REFERENCES}

1. Al Talalwah W. A new concept and classification of corona mortis and its clinical significance. Chin J Traumatol. 2016; 19(5): 251-254, doi: 10.1016/j.cjtee.2016.06.004, indexed in Pubmed: 27780502.

2. Ates $M$, Kinaci $E$, Kose $E$, et al. Corona mortis: in vivo anatomical knowledge and the risk of injury in totally extraperitoneal inguinal hernia repair. Hernia. 2016; 20(5): 659-665, doi: 10.1007/s10029-015-1444-8, indexed in Pubmed: 26621137.

3. Balega J, Van Trappen PO. The sentinel node in gynaecological malignancies. Cancer Imaging. 2006; 6: 7-15, doi: 10.1102/1470-7330.2006.0002, indexed in Pubmed: 16520291.

4. Berberoğlu M, Uz A, Ozmen MM, et al. Corona mortis: an anatomic study in seven cadavers and an endoscopic study in 28 patients. Surg Endosc. 2001; 15(1): 72-75, doi: 10.1007/s004640000194, indexed in Pubmed: 11210207.

5. Bogliatto F, Bornstein J. Surgical procedures of preneoplastic and neoplastic conditions. Vulvar Disease. 2019: 401-412, doi: 10.1007/978-3-319-61621-6_59.

6. Borgno G, Micheletti L, Barbero M, et al. Topographic distribution of groin lymph nodes. A study of 50 female cadavers. J Reprod Med. 1990; 35(12): 1127-1129, indexed in Pubmed: 2283629.

7. Cesmebasi A, Baker A, Du Plessis M, et al. The surgical anatomy of the inguinal lymphatics. Am Surg. 2015; 81(4): 365-369, indexed in Pubmed: 25831182.

8. Chung S, Chengtsin LIU. The origin of the obturator artery and the blood vessels related to the femoral ring. Acta Anat Sinica. 1964; 2: 181-187.

9. Cibula D, Abu-Rustum NR. Pelvic lymphadenectomy in cervical cancer--surgical anatomy and proposal for a new classification system. Gynecol Oncol. 2010; 116(1): 33-37, doi: 10.1016/j.ygyno.2009.09.003, indexed in Pubmed: 19837449.

10. Cooper $A$. The anatomy and surgical treatment of inguinal and congenital hernia. Edinb Med Surg J. 1806; 2(6): 241-251.

11. Darmanis S, Lewis $A$, Mansoor A, et al. Corona mortis: an anatomical study with clinical implications in approaches to the pelvis and acetabulum. Clin Anat. 2007; 20(4): 433-439, doi: 10.1002/ca.20390, indexed in Pubmed: 16944498.

12. Drewes PG, Marinis SI, Schaffer JI, et al. Vascular anatomy over the superior pubic rami in female cadavers. Am J Obstet Gynecol. 2005; 193(6): 2165-2168, doi: 10.1016/j. ajog.2005.07.033, indexed in Pubmed: 16325635.
13. Faure JP, Hauet $T$, Scepi $M$, et al. The pectineal ligament: anatomical study and surgical applications. Surg Radiol Anat. 2001; 23(4): 237-242, doi: 10.1007/s00276-0010237-1, indexed in Pubmed: 11694967.

14. Gobrecht U, Kuhn A, Fellman B. Injury of the corona mortis during vaginal tape insertion (TVT-Secur ${ }^{\mathrm{TM}}$ using the U-Approach). Int Urogynecol J. 2011; 22(4): 443-445, doi: 10.1007/s00192-010-1355-2, indexed in Pubmed: 21243484.

15. Han Y, Liu P, Chen C, et al. A digital anatomical study of the corona mortis in females. Minim Invasive Ther Allied Technol. 2017; 26(2): 111-118, doi: 10.1080/13645706.2016.1236818, indexed in Pubmed: 27830594.

16. Hubka P, Svabik K, Martan A, et al. A serious bleeding complication with injury of the corona mortis with the TVT-Secur procedure: two cases of contact of TVT-S with the corona mortis during cadaver study. Int Urogynecol J. 2010; 21(9): 1179-1180, doi: 10.1007/s00192-010-1190-5, indexed in Pubmed: 20532870.

17. Kale A, Biler A, Terzi $H$, et al. Laparoscopic pectopexy: initial experience of single center with a new technique for apical prolapse surgery. Int Braz J Urol. 2017; 43(5): 903-909, doi: 10.1590/S1677-5538.IBJU.2017.0070, indexed in Pubmed: 28727377.

18. Kashyap S, Diwan $Y$, Mahajan S, et al. The majority of corona mortis are small calibre venous blood vessels: a cadaveric study of north indians. Hip Pelvis. 2019; 31(1): 40-47, doi: 10.5371/hp.2019.31.1.40, indexed in Pubmed: 30899714.

19. Kinman CL, Agrawal A, Deveneau NE, et al. Anatomical relationships of burch colposuspension sutures. Female Pelvic Med Reconstr Surg. 2017; 23(2): 72-74, doi: 10.1097/ SPV.0000000000000341, indexed in Pubmed: 27682747.

20. Kocjancic E, Crivellaro S, Oyama IA, et al. Transobturator tape in the management of female stress incontinence: clinical outcomes at medium term follow-up. Urol Int. 2008; 80(3): 275-278, doi: 10.1159/000127340, indexed in Pubmed: 18480630.

21. Kumar D, Rath G. Anomalous Origin of Obturator Artery from the Internal Iliac Artery. Int J Morphol. 2007; 25(3), doi: 10.4067/s0717-95022007000300028.

22. Larsson PG, Teleman P, Persson J. A serious bleeding complication with injury of the corona mortis with the TVT-Secur procedure. Int Urogynecol J. 2010; 21(9): 1175-1177, doi: 10.1007/s00192-010-1103-7, indexed in Pubmed: 20179906.

23. Lau H, Lee F. A prospective endoscopic study of retropubic vascular anatomy in 121 patients undergoing endoscopic extraperitoneal inguinal hernioplasty. Surg Endosc. 2003; 17(9): 1376-1379, doi: 10.1007/s00464-003-8800-y, indexed in Pubmed: 12802654.

24. Leite TF, Pires LA, Goke K, et al. Corona Mortis: anatomical and surgical description on 60 cadaveric hemipelvises. Rev Col Bras Cir. 2017; 44(6): 553-559, doi: 10.1590/010069912017006001, indexed in Pubmed: 29267551.

25. Micheletti L, Preti M. Surgery of the vulva in vulvar cancer. Best Pract Res Clin Obstet Gynaecol. 2014; 28(7): 1074 -1087, doi: 10.1016/j.bpobgyn.2014.07.011, indexed in Pubmed: 25132277.

26. Missankov AA, Asvat R, Maoba KI. Variations of the pubic vascular anastomoses in black South Africans. Acta Anat 
(Basel). 1996; 155(3): 212-214, doi: 10.1159/000147807, indexed in Pubmed: 8870790.

27. Montoya TI, Street JJ, Corton MM. Anatomic relationships of single-incision midurethral slings. Am J Obstet Gynecol. 2013; 208(1): 75.e1-75.e5, doi: 10.1016/j. ajog.2012.10.004, indexed in Pubmed: 23099191.

28. Morcel K, Camborieux L, Guerrier D. Programme de Recherches sur les Aplasies Müllériennes. Mayer-Rokitansky-Küster-Hauser (MRKH) syndrome. Orphanet J Rare Dis. 2007; 2: 13, doi: 10.1186/1750-1172-2-13, indexed in Pubmed: 17359527.

29. Nayak SB, Deepthinath R, Prasad AM, et al. A South Indian cadaveric study on obturator neurovascular bundle with a special emphasis on high prevalence of 'venous corona mortis'. Injury. 2016; 47(7): 1452-1455, doi: 10.1016/j. injury.2016.04.032, indexed in Pubmed: 27156835.

30. Ohba $Y$, Todo $Y$, Akashi $D$, et al. Incidence of metastasis in the circumflex iliac nodes distal to the external iliac nodes in ovarian cancer. Gynecol Oncol. 2012; 126(3): 387-390, doi: 10.1016/j.ygyno.2012.05.031, indexed in Pubmed: 22664060.

31. Okcu G, Erkan S, Yercan HS, et al. The incidence and location of corona mortis: a study on 75 cadavers. Acta Orthop Scand. 2004; 75(1): 53-55, doi: 10.1080/00016470410001708100, indexed in Pubmed: 15022807.

32. Pellegrino A, Damiani GR, Marco S, et al. Corona mortis exposition during laparoscopic procedure for gynecological malignancies. Updates Surg. 2014; 66(1): 65-68, doi: 10.1007/s13304-013-0245-9, indexed in Pubmed: 24390752.

33. Pick J, Anson B, Ashley F. The origin of the obturator artery. A study of 640 body-halves. Am J Anat. 1942; 70(2): 317-343, doi: 10.1002/aja.1000700206.

34. Pulatoğlu Ç, Doğan O, Medisoğlu MS, et al. Surgical anatomy of the pectineal ligament during pectopexy surgery: The relevance to the major vascular structures. Turk J Obstet Gynecol. 2020; 17(1): 21-27, doi: 10.4274/ tjod.galenos.2020.21284, indexed in Pubmed: 32341826.

35. Rajan S, Kohli N. Retropubic hematoma after transobturator sling procedure. Obstet Gynecol. 2005; 106(5 Pt 2): 1199-1202, doi: 10.1097/01.AOG.0000161063.55834.27, indexed in Pubmed: 16260571.

36. Rusu MC, Cergan R, Motoc AG, et al. Anatomical considerations on the corona mortis. Surg Radiol Anat. 2010; 32(1): 17-24, doi: 10.1007/s00276-009-0534-7, indexed in Pubmed: 19636491.

37. Sakthivelavan S, Sendiladibban S, Aristotle S, et al. Corona mortis: a case report with surgical implications. Int J Anat Var. 2010; 3: 103-105.

38. Sanna B, Henry BM, Vikse J, et al. The prevalence and morphology of the corona mortis (Crown of death): A meta-analysis with implications in abdominal wall and pelvic surgery. Injury. 2018; 49(2): 302-308, doi: 10.1016/j. injury.2017.12.007, indexed in Pubmed: 29241998.

39. Sañudo JR, Mirapeix R, Rodriguez-Niedenführ $M$, et al. Obturator artery revisited. Int Urogynecol J. 2011; 22(10):
1313-1318, doi: 10.1007/s00192-011-1467-3, indexed in Pubmed: 21655978.

40. Sañudo JR, Roig M, Rodriguez A, et al. Rare origin of the obturator, inferior epigastric and medial circumflex femoral arteries from a common trunk. J Anat. 1993; 183 (Pt 1): 161-163, indexed in Pubmed: 8270471.

41. Sarikcioglu L, Sindel M, Akyildiz F, et al. Anastomotic vessels in the retropubic region: corona mortis. Folia Morphol. 2003; 62(3): 179-182, indexed in Pubmed: 14507043.

42. Selçuk i, Tatar i, Fırat A, et al. Is corona mortis a historical myth? A perspective from a gynecologic oncologist. J Turk Ger Gynecol Assoc. 2018; 19(3): 171-172, doi: 10.4274/ jtgga.2018.0017, indexed in Pubmed: 29699960.

43. Selçuk i, Uzuner B, Boduç E, et al. Pelvic lymphadenectomy: Step-by-step surgical education video. J Turk Ger Gynecol Assoc. 2020; 21(1): 66-69, doi: 10.4274/ jtgga.galenos.2019.2018.0167, indexed in Pubmed: 30905139.

44. Shen P, Conforti AM, Essner R, et al. Is the node of Cloquet the sentinel node for the iliac/obturator node group? Cancer J. 2000; 6(2): 93-97, indexed in Pubmed: 11069226.

45. Skandalakis L, Skandalakis J. Surgical Anatomy and Technique. A Pocket Manual. 3rd ed. Springer-Verlag, New York 2009: 689-701.

46. Stavropoulou-Deli A, Anagnostopoulou S. Corona mortis: anatomical data and clinical considerations. Aust N Z J Obstet Gynaecol. 2013; 53(3): 283-286, doi: 10.1111/ajo.12076, indexed in Pubmed: 23551084.

47. Steinke $H$, Wiersbicki $D$, Völker $A$, et al. The fascial connections of the pectineal ligament. Clin Anat. 2019; 32(7): 961969, doi: 10.1002/ca.23445, indexed in Pubmed: 31381189.

48. Takeshita S, Todo Y, Okamoto K, et al. Incidence of metastasis in circumflex iliac nodes distal to the external iliac nodes in cervical cancer. J Gynecol Oncol. 2016; 27(4): e42, doi: 10.3802/jgo.2016.27.e42, indexed in Pubmed: 27102250.

49. Tantchev L. Corona mortis: clinical and anatomical details. AkushGynecol. 2019; 58(1): 24-28.

50. Todo Y, Yamazaki H, Takeshita S, et al. Close relationship between removal of circumflex iliac nodes to distal external iliac nodes and postoperative lower-extremity lymphedema in uterine corpus malignant tumors. Gynecol Oncol. 2015; 139(1): 160-164, doi: 10.1016/j.ygyno.2015.07.003, indexed in Pubmed: 26186910.

51. Tornetta P, Hochwald N, Levine R. Corona mortis. Clin Orthop Relat Res. 1996; 329: 97-101, doi: 10.1097/00003086$199608000-00012$.

52. Veit-Rubin N, Dubuisson J, Ford A, et al. Burch colposuspension. Neurourol Urodyn. 2019; 38(2): 553-562, doi: 10.1002/nau.23905, indexed in Pubmed: 30620096.

53. Vincent RL, Miles M. Laparoscopic Burch colposuspension for stress urinary incontinence: When, how, and why? OBG Manag. 2003; 15(2): 20-34.

54. Won HS, Kim JH, Lee UY, et al. Topographical relationships between the obturator nerve, artery, and vein in the lateral pelvic wall. Int Urogynecol J. 2016; 27(2): 213-218, doi: 10.1007/s00192-015-2806-6, indexed in Pubmed: 26224385. 